\title{
SUBJETIVIDADE EM MOVIMENTO: O MST NO RIO GRANDE DO NORTE
}

\author{
Jáder Ferreira Leite \\ Magda Dimenstein \\ Universidade Federal do Rio Grande do Norte
}

RESUMO: Este trabalho propõe uma discussão acerca dos processos de subjetivação em trabalhadores sem-terra acampados, vinculados ao Movimento dos Trabalhadores Sem Terra (MST) no Rio Grande do Norte. Elegemos como dispositivos de subjetivação a vivência cotidiana do acampamento e o discurso político do MST. Foram utilizadas entrevistas semi-estruturadas junto a dezesseis trabalhadores e trabalhadoras e observações das práticas cotidianas do grupo. Os resultados apontam a emergência de produções subjetivas articuladas ao projeto coletivista político-ideológico do MST, materializadas na figura do "Sem-Terra", bem como modos singulares de subjetivação que implicam na criação de espaços de ruptura que, muitas vezes, se chocam com a perspectiva macropolítica desse movimento social. Pretendemos enfatizar que os novos arranjos subjetivos que emergem e se movimentam são efeitos dos modos de uso do corpo e de apropriação do espaço ocupado e configuram-se como elementos imprescindíveis de sustentação do movimento enquanto uma experiência de resistência no seio do capital.

PALAVRAS-CHAVE: produção de subjetividade; MST; práticas cotidianas.

\section{SUBJECTIVITY IN MOVEMENT: THE MST IN RIO GRANDE DO NORTE}

ABSTRACT: The present investigation is aimed at pointing out the MST (Landless Workers Movement) as a social movement that concurs to the production of subjectivities of a group of workers in MST settlements in the Brazilian State of Rio Grande do Norte. The authors stressed that those workers' subjectivities are in consonance with their use of their bodies and with the appropriation they make of the territory they've occupied. Semi-structured interviews were conducted with sixteen settlers, as well as observations of the group's daily practices. Results show the emergency of subjective production articulated to the MST's political-ideological project, materialized as the illustration of the "Landless Man" as well as singular manners of subjective production that implicate the need for desire investments, the sensitive reality of the settlers which are often in conflict with the structural perspective or macropolitics glimpsed by the MST.

KEYWORDS: production of subjectivity; MST; daily practices.

Este trabalho propõe uma discussão acerca dos processos de subjetivação em trabalhadores sem-terra, vinculados ao MST e instalados em uma área de acampamento no estado do Rio Grande do Norte. Elegemos como dispositivos de subjetivação a vivência cotidiana do acampamento, como também o discurso político do MST, com o qual os trabalhadores acampados passam a ter contato através das ações dos militantes e coordenadores do referido movimento.

A concepção de subjetividade que norteia este trabalho não se assemelha a um sujeito psicológico abstrato, interiorizado, racional e em dicotomia com os processos sociais. Além disso, entendemos que sua produção pode voltarse tanto no sentido de reprodução de modelos dominantes das relações sociais, como também de criação de espaços de ruptura, de modelos que redefinem o campo social. Nessa ótica, o MST está sendo entendido enquanto um movimento social que, ao defender um modelo de organização coletiva da sociedade e das subjetividades, colocase como um agente de subjetivação, com o qual os trabalhadores acampados passam a ser afetados por meio de falas, rituais, programações e mobilizações no cotidiano do acampamento (Leite, 2003).

\section{MST e Produção de Subjetividade}

O MST se apresenta no cenário brasileiro, desde o início dos anos oitenta, como um dos atores centrais na luta pela reforma agrária. Para alguns teóricos do MST, a exemplo de Fernandes e Stédile (1999), sua luta consiste em denunciar os efeitos sócio-econômicos do avanço do capital no campo, do desenraizamento por ele provocado e da legião de excluídos que criou, em função do seu caráter extremamente concentracionista de terras, processo também denominado de modernização conservadora (Graziano da Silva, 1981).

Como efeito desse avanço do capital no meio rural, tivemos a geração de uma forte exclusão dos pequenos trabalhadores rurais do acesso à terra, dificultando o avanço produtivo de suas lavouras, inviabilizando um projeto de agricultura familiar e lançando-os numa miséria profunda e num êxodo rural sem precedentes, contribuindo para um crescimento assombroso da população urbana no país. ${ }^{1}$

Ao que nomeia de Capitalismo Mundial Integrado, Guattari (1997) comenta que o seu avanço sobre os diversos pontos do planeta deu-se por meio de um processo de transformação dos territórios existentes, ocorrido tanto em 
extensão, "ampliando seu domínio sobre o conjunto da vida social, econômica e cultural do planeta", quanto em intenção, "infiltrando-se no seio dos mais inconscientes estratos subjetivos" (p. 33). Assim, além de precarizar ainda mais as diversas formas de relação de trabalho e produção de inúmeros agricultores familiares, a máquina capitalista provocou uma desterritorialização de ordens subjetivas, investimentos e representações que tinham como base a organização camponesa, o trabalho familiar e os laços comunitários.

No entanto, a forma do MST empreender a luta pela terra, a partir do cenário acima exposto, se desenvolveu de modo singular em relação a inúmeros outros movimentos sociais ligados à questão da reforma agrária. Nesse trabalho, damos destaque a dois desses modos: as ações de ocupação de terras privadas, públicas e margens de rodovias para constituição dos acampamentos de trabalhadores semterra e um arrojado processo de formação política, seja de sua militância, seja de sua base social, particularmente através do princípio organizativo da disciplina. Embora a estratégia de ocupação de terras não seja uma ação adotada exclusivamente pelo MST (Navarro, 1998), assim como o processo de formação de seus quadros, o referido movimento investe de modo sistemático nessas duas modalidades, levando-o a uma popularidade nacional e mesmo internacional em que se estabelece uma polêmica em torno de tais ações.

No que diz respeito à ocupação de terras, Fernandes (2000, p.286) destaca que ela inaugura uma luta em "regiões onde o capital já se territorializou". Nesses termos, os acampamentos são tidos como espaços de resistência. O citado autor faz uso de termos como "territorialização" e "desterritorialização" para apontar o complexo movimento em que, ao avançar no campo, provocando processos de desterritorialização conforme destacado acima, o capital reterritorializa modos de organização social em que terão centralidade os princípios de exploração e expropriação dos trabalhadores rurais. Refletindo tais termos, a partir da perspectiva teórica de Deleuze e Guattari, Haesbaert (2004) destaca:

Os territórios sempre comportam dentro de si vetores de desterritorialização e de reterritorialização. Muito mais do que uma coisa ou objeto, o território é um ato, uma ação, uma rel-ação [sic], um movimento (de territorialização e desterritorialização), um ritmo, um movimento que se repete e sobre o qual se exerce um controle. (p.127)

Sobre o impacto da desterritorialização provocada pelo capital na esfera das subjetividades, Rolnik (2003) registra que esse efeito é a territorialização de um modelo que desemboca num território subjetivo elitizado e que "fora desse território corre-se o risco de morte social - por exclusão, humilhação, miséria, quando não por morte concreta, como uma célula morta do corpo coletivo" (p. 260). Um território do capital que, de acordo com a autora, conforma um lado de dentro, tipo subjetividade-luxo com as inúmeras promessas do capital e um lado de fora, "a abjeção das subjetividades-lixo e seus cenários de horror feitos de guerra, favela, tráfico, sequiestro, fila de hospital, crianças desnutridas, gente sem teto, sem terra, sem camisa, sem papel - boat people vagando no limbo sem lugar onde ancorar" (Rolnik, 2003, p. 260).

Entendemos com isso que as ocupações de terra e a constituição dos acampamentos acabam por imprimir um outro ritmo nesse processo, em que uma resistência ou uma negativa a tais efeitos do capital passam a compor um jogo de forças no campo social. Em que a luta de seus participantes torna-se uma luta contra os horrores das subjetividades-lixo. Tomados como recortes territoriais, mesmo que precariamente, os acampamentos vão produzir/reproduzir um modo de funcionamento em que a ação dos atores envolvidos irá desenhando e redesenhando o acampamento enquanto um campo de forças, em que agenciamentos de diversos elementos vão compor tal ação (políticos, espaciais, subjetivos).

Nesse caso, a noção de território ganha uma dimensão para além de uma associação com um espaço político plenamente demarcado, mas é destacada, conforme assinala Guattari (apud Silva, 2000):

(...) O território pode ser relativo tanto a um espaço vivido, quanto a um sistema percebido no seio do qual o sujeito se sente em "casa". O território é sinônimo de apropriação, de subjetivação fechada sobre si mesma. Ele é o conjunto dos projetos e das representações nos quais vai desencadear, pragmaticamente, toda uma série de comportamentos, de investimentos, nos tempos e nos espaços sociais, culturais, estéticos, cognitivos (p.06).

Assim, o acampamento passa a compor modos de experimentação em que se tenta ou busca construir um território existencial auto-referencial (Guattari, 2000), onde se dá um agenciamento de objetivos, anseios, investimentos de desejo, projetos individuais e coletivos mediados pela terra-objeto de luta. É também nessa dimensão territorial que entra em cena a segunda modalidade por nós destaca como característica singular da luta do MST: o processo de formação política dos trabalhadores sem-terra. Essa modalidade é especialmente investida no acampamento, tornando-o um espaço privilegiado de formação. Esta, por sua vez, passa a ser tida como um ingrediente a mais que conforma, junto aos trabalhadores acampados, a vivência de um território existencial específico.

Por não ter havido ainda a conquista da terra, os acampados vivem um tempo de espera (Bonavigo, 1998) e é nesse tempo que o trabalho de formação irá se destacar. O que está em jogo, em linhas gerais, na formação do tra- 
balhador sem-terra e do militante é a fabricação de um modelo subjetivo que se coadune com os projetos do movimento: o Sem Terra. ${ }^{2}$

Em investigações anteriores (Leite, 2003; Leite \& Dimenstein, 2003), destacamos que a tentativa de construção de um sujeito Sem Terra não mobiliza apenas o nível de sua consciência ou de uma mudança no plano ideológico dos trabalhadores, como sugere um de seus teóricos (Bogo, 2000), mas aborda o nível de suas experiências subjetivas, tocando-as e buscando sua modificação (Bonavigo, 1998). Para tanto, a concepção de subjetividade adotada neste trabalho insere-a no âmbito de sua produção ou de sua fabricação social e histórica (Pelbart, 2003), na qual diversos fatores ou instâncias postos em conexão (relações de saber/ poder, institucionais, lingüísticos, culturais, econômicos, tecnológicos), se articulam para gestar diversas formas subjetivas, que tanto podem se exprimir numa escala pessoal, quanto coletiva (Guattari, 2000), em constante processualidade.

Se tomarmos os elementos destacados por Bogo (2000) no que diz respeito aos traços que identificam o Sem Terra, como "organização política, identidade, ideologia e valores" (p. 22); "melhoramento do comportamento" e "limpeza dos vícios que se acumularam em cada consciência" (p. 33) e uma superação da dicotomia público-privado, estamos diante de traços que não se resumem ao plano de uma racionalidade egóica (Guattari \& Rolnik, 1986), mas implica na participação de instâncias outras (inconscientes, afetivas) que promove um redimensionamento nos modos de agir, sentir, relacionar-se, envolvendo, inclusive, aspectos de uma versão privada da subjetividade. Assim, o que comumente é entendido na linguagem do movimento como um processo de conscientização ou formação dos trabalhadores e militantes, a nosso ver, diz respeito a algo que é mais complexo, mais arrojado na produção dessa subjetividade.

A partir do exposto, nosso estudo, realizado em um acampamento da região agreste do Estado do Rio Grande do Norte, objetivou investigar em que medida o ambiente sociocultural inaugurado pelo MST, por meio de seu projeto de produção de um sujeito militante - o Sem Terra - possibilita reordenamentos nas subjetividades de seus habitantes: os trabalhadores da base social do movimento.

Destacamos que um dos elementos trazidos por esse "novo" ambiente sociocultural que orienta a passagem do "sem-terra" ao "Sem Terra" trata-se do que Gaiger (1994) nomeia de "práxis coletiva do MST". Tal práxis guia-se por princípios organizativos ${ }^{3}$ de contestação do modelo hegemônico de organização da sociedade capitalista, assim como aborda um tipo de militância que tece críticas ao modo vigente de organização social, adotando práticas de "solidariedade, fidelidade e firmeza na luta" (Gaiger, 1994, p. 185), incorporando suas aspirações pessoais ao projeto maior demandado por seu grupo social. Portanto, para nós, esse ambiente sociocultural investido pelo MST conforma em si um regime de subjetivação que será posto em prática pelo trabalho de formação ao conjunto dos acampados.

\section{Os Procedimentos Metodológicos da Pesquisa}

O acampamento Garavelo II, localizado na região agreste do Rio Grande do Norte e com 16 famílias habitantes da área, passou a ser o recorte específico que possibilitou-nos conhecer como o ambiente sociocultural inaugurado pelo MST concorre na produção de subjetividade, no contexto do cotidiano dos trabalhadores e trabalhadoras sem-terra. Buscamos abordar nossas indagações de pesquisa por meio de um roteiro de entrevista individual semi-estruturada e da observação das práticas cotidianas dos trabalhadores acampados (Certeau, 1996). A elaboração do roteiro de entrevista foi por nós pensada a partir de alguns critérios que envolvem as formas de acessar as subjetividades enquanto processo ou produção. Nardi (2002) a esse respeito, comenta:

Os processos de subjetivação podem ser compreendidos, por sua vez, a partir da análise da maneira como cada indivíduo se relaciona com o regime de verdades próprio a cada período, ou seja, a maneira como o conjunto de regras que define cada sociedade é experienciado em cada trajetória de vida. (p.21)

De modo complementar, as observações de campo, conversas informais, participação em assembléias dos acampados e mobilizações coordenadas pelo MST na cidade de Natal/RN e acompanhamento de atividades rotineiras no acampamento possibilitaram uma articulação com os dados colhidos nas entrevistas e foram analisadas à luz da contribuição teórica de Certeau (1996) a respeito das práticas cotidianas.

A questão importante levantada por este autor está em demonstrar que, na construção do cotidiano, os indivíduos não estão meramente na posição de reprodução de padrões socioculturais vigentes. Assim, mais do que sujeitos disciplinados, o cotidiano se produz em meio a uma multiplicidade de táticas que burlam as formas tradicionais de orientação do poder: é regido por uma antidisciplina (Certeau, 1996).

Por meio de tal perspectiva pudemos vislumbrar o modo como os trabalhadores acampados se relacionam com a práxis coletiva do MST, seja no sentido de incorporá-la no seu cotidiano, seja de confrontamento diante de um regime de subjetivação produzido pelo movimento.

\section{O Acampamento Garavelo II: Vivendo a Vida na Margem}

Disposto espacialmente na margem de uma rodovia não-asfáltica que liga o município de Pureza a João Câmara, o acampamento Garavelo II, composto de dezesseis 
barracos posicionados de forma linear, surgiu a partir de uma ocupação efetuada em setembro de $1999 .{ }^{4}$ A partir de então, uma série de atividades passou a ser planejada e executada tanto no espaço do acampamento, quanto externamente, no sentido de abertura de um processo de negociação com o Instituto Nacional de Colonização e Reforma Agrária (INCRA), do Estado do Rio Grande do Norte.

Nessas atividades, os trabalhadores passaram a ter contatos mais aproximados com os discursos e práticas dos militantes do MST estabelecidos com o início da ocupação, passando pela estruturação do acampamento até o convívio continuado com reuniões, assembléias, participação em cursos de formação em outras cidades, viagens a outras áreas de acampamento e assentamentos e à capital do Estado para a realização de marchas de protesto e mobilizações programadas pelo MST/RN.

Nessa etapa, um dos principais investimentos do MST é a realização de um trabalho de formação de sua base social que trata de produzir no cotidiano do acampamento procedimentos de convivência entre seus habitantes pautados em valores coletivistas, na manutenção e permanência da ocupação e de regras de convívio comunitário, bem como de reprodução da estrutura organizativa do movimento.

Dentre tais procedimentos, um que se destaca é o princípio organizativo da disciplina. A idéia desse princípio, segundo Bonavigo (1998), vem do fato de os dirigentes do MST considerarem alguns padrões de comportamento do camponês como "desvios" que precisam passar de um modo individual para um modo coletivo.

Como a disciplina faz alusão à observação e ao cumprimento das decisões tomadas pelo movimento, é exigida dos trabalhadores a incorporação desse modelo de organização interna. Estamos, por assim dizer, no campo de exercício das relações de saber/poder, para usarmos uma expressão de Foucault (1984). Isto está posto, especialmente, na busca de traçar modos de conduta no acampamento, nas formas de convivência, nas posturas consideradas certas e a serem adotadas entre os membros do acampamento, ou seja, na busca de uma construção de práticas que promovam uma subjetivação tipo militante, guiada pela práxis coletiva.

As falas de I. e M. podem integrar nosso pensamento:

DIÁLOGO 01 (I., trabalhador acampado, 34 anos)

J. (pesquisador): O que você faz pra se manter aqui? Pra não sair daqui?

I. (entrevistado): Gente... o que se faz pra se manter aqui? Tem que ser comportado, tem que ser amigo de todos nós companheiros que tamo aqui dento. Porque se não for comportado, nem se for companheiro dos outros, com certeza, vai embora, n/é? Isso é que tem no acampamento: tem que ser amigo, tem que ser companheiro. E se não for, vai uma assembléia, um negócio, e o povo vai dizer, e o companheiro sai, n'é? Sai, mas quando é vontade da gente, porque um ou dois não pode falar por dez ou por quinze. Aí, esse é o problema, aí tem, pra não sair tem que se comportar muito bem, não bagunçar, não de exagerar, não esculhambar com ninguém. Tem que ser um cara firme, porque senão pode perder o futuro que vem por aí.

DIÁLOGO 02 (M., trabalhador acampado, 26 anos)

J. (...) Que mais você faz prá continuar aqui, ficar (no acampamento)?

M. Aqui, porque tem uma norma. Quando aqui, se você passou do limite, assim, tem uma desavença com um companheiro, essas... aqui não pode acontecer isso, aí nós, cada um faz por si, não acontecer isso, não ando bebendo prá... porque às vezes, o "caba", o caba civilizado, ele tando bom assim, aí toma uma pinga, você já não é aquela mesma pessoa. Eu procuro fazer isso, "mode" prá não aborrecer nossos companheiro aqui.

J. Você falou que tem uma norma aqui. Como é essa norma?

M. Uma norma assim é como uma lei, porque nós não pode... nós não pode chegar assim, discutir com ninguém, porque se, a norma aqui é essa: se eu discutir, se eu puxei, se eu tenho uma arma e andar puxando, isso não pode acontecer. Aí, se eu fizer isso, o pessoal, não é eu que v..., não é uma pessoa que vai botar, é o pessoal todinho. Aí, a norma é meia... pesada por causa disso. Porque se eu fizer isso, posso tá com dois ou três anos, o povo bota prá fora.

J. Aí como foi que vocês chegaram a essa norma?

M. Isso aí nós se senta, em reuniões, aí debate isso aí, conversa com tudinho e todo mundo aceita e isso... todo mundo aceita e... aí é criado.

Uma questão por nós observada é que a disciplina desencadeia questões ligadas às relações entre os homens e as mulheres no acampamento. A busca por uma "conduta correta", pela obediência à "lei" apregoada no acampamento tem livrado algumas mulheres de atos de violência física pelos seus companheiros:

DIÁLOGO 01 (M. L., trabalhadora acampada, 39 anos)

J.: E assim, por exemplo, na relação com tua família, com teu marido, tu sente que mudou alguma coisa depois que veio pra o acampamento?

M.L.: Mudou.

J.: O que foi que mudou?

M.L.: Mudou porque antes, ele, ele bebia muito, batia muito em mim, e agora ele num faz mais. Mudou, nessa parte aí mudou muito, de minha vida com ele, sobre o viver da gente, num é pra dizer a verdade, n/é? Pronto, sobre isso aí, ele mudou muito, ele num bateu mais 
em mim, é um bom pai pros filho, é um bom marido pra mim, tá sendo, n/é, graças a Deus. Que Jesus abençoe assim, e aí, tamo levando a vida.

DIÁLOGO 02 (D., trabalhadora acampada, 54 anos)

J.: É... e assim, por exemplo, na relação da senhora com seu esposo, é... a senhora sente que mudou alguma coisa depois que tão aqui no acampamento?

D.: Mudou, mudou muito. Mudou, porque aí... ele só bebe no sábado e no domingo. Aí, dorme tranqüilo comi... aqui mais eu. Aí, eu digo a ele porque, eu tou passada de dizer a ele: "N., olha, a pessoa prá tudo tem controle, e tudo tem limite, n/é?". Aí, ele bebe mais pouco, não vem me aborrecer e tudo bem, melhorou qualquer coisa.

J.: Por que é que a senhora acha que ele bebe mais pouco agora?

D.: É porque ele tem que be... Agora ele bebe mais pouco porque aqui tem lei, não sabe? E... M. (militante que mora no acampamento) disse: "Olha, aqui a pessoa pode vim e tomar sua chamadinha (cachaça), chegar na sua barraca e dor... e se deitar. Aí, ele quis bagunçar aqui. Eu digo: "Não, olhe, prá bagunçar, não. Você bagunça lá na sua casa, agora aqui, não. Agora, aqui... aqui você não bagunça não, porque aqui tem respeito e tem moral. Não é assim, não". Aí, ele disse... por Deus que ele reconhece o erro dele aí disse: "É mesmo, eu tou errado." Eu digo: “- Pois é, você tem de se controlar, se controlar porque tudo de mais é muito." Aí ninguém pode fazer... encher a cara de cana e fazer o que bem quer, n/é? Tem que ter limite, aí é por isso que ele se controlou mais. Que eu tenho batido em cima dele, porque se não for assim, não vai não.

A tentativa de subjetivação caminha no sentido de tornar o acampamento um espaço de harmonia, de vivência coletiva, em que os objetivos do grupo se sobreponham aos interesses pessoais. Quando relacionamos os aspectos básicos elencados pelos acampados sobre as formas adequadas de relacionamento no acampamento, como: fazer amizades, ser bom vizinho, demonstrar união, não procurar confusão, respeitar o outro, repartir as doações conseguidas fora do acampamento (roupas, alimentos, gás para fazer fogo, etc.), socorrer alguém que não tenha alimento, não consumir cachaça no acampamento; tais regras de convivência se aproximam com as orientações dadas pelos militantes nas assembléias com os trabalhadores. Por sua vez, o universo pessoal, a experiência do acampamento vivida em sua singularidade pelos acampados e os conflitos que daí se estabelecem levam à adoção de medidas que burlam, algumas vezes, as diretrizes internas do movimento, produzindo uma espécie de antidisciplina (Certeau, 1996) ou mesmo a construção de arranjos singulares de subjetivação.
Certeau (1996, p.100-101) destaca que, diante de um poder disciplinar, de uma tentativa de homogeneização dos indivíduos, nesse caso uma subjetivação militante pautada no modelo dos Sem Terra, estes se apresentam com potencial para burlar tal tentativa, utilizando-se de operações multiformes, práticas múltiplas que se inserem no campo daquilo que nomeia de "táticas".

Nesses termos, o cotidiano é tecido em meio a esse emaranhado de práticas que permitem uma reapropriação, mesmo que precária, do ambiente sociocultural compartilhado pelo MST:

DIÁLOGO 01 (I., trabalhador acampado, 34 anos)

J.: I., você acha que as pessoas do acampamento são unidas?

I.: Rapaz, uns, tem uns que são tranqüilamente unido, tem uns que... Só tem hora que tão unido, mas tem hora que... Fica por aí, no rem, rem, rem, pá, e conversa, e tal. Mas aí, é o problema que nem eu te falei, às vezes, porque às vez, a pessoa tá de cabeça quente naquele momento que o cabra, n/é? chega também. Aí, se deixar esfriar a cabeça, fica tudo unido. Chegar, de cabeça quente, aí, esquenta mais, e fica todo mundo doido.

J.: Porque você acha que, assim, algumas pessoas esquentam a cabeça?

I.: É, porque eu acho que cada um tem o seu problema, n/é? Cada um tem o seu problema e, você sabe, o homem é um segundo pra ter aquele momento de loucura, como mulher também, eu acho que deve ser a mesma coisa. Às vez, você tá perturbado, assim, vê, tá faltando alguma coisa na sua casa, na casa do camarada. Às vez, tá parado, olhando a sua família ali. Às vez, tá... tá faltando, não tem nada, um recurso assim, n/é, por... naquele momento. E, é, naquele momento que, às vez, você fica uma pessoa, o cara vem com uma pessoa, e estranha ele. Pensa na família, pensa em chegar o dia de amanhã e não ter o dinheiro de fazer sua feira. E... Pensa em muitas coisas, e é por isso que esquenta, às vez a cabeça do camarada.

Esse movimento multiforme do campo das táticas pôde ser observado no Acampamento Garavelo II e está relacionado, especialmente, com a aspiração maior do grupo acampado: a terra.

Nossa permanência no acampamento possibilitou conhecer um acontecimento curioso: há, por parte dos acampados, uma certa apropriação de uma faixa de terra da propriedade reivindicada. Essa faixa avança a propriedade em torno de $30 \mathrm{~m}$ e é bastante utilizada pelos mesmos como extensão da barraca, uma espécie de quintal.

A "conquista" desta faixa parece ser algo já assimilado pelo gerente da propriedade e pelos acampados que nela já fizeram diversas aberturas na cerca e realizam boa parte de suas atividades diárias: cozinham, criam animais de 
pequeno porte, realizam pequenas plantações, crianças brincam, etc.

Essa espécie de incorporação da faixa de terra acontece a despeito das orientações do movimento de não recomendar a entrada na área, bem como do princípio de proteção ao patrimônio privado. No entanto, já se registraram conflitos entre os trabalhadores e o gerente da fazenda em torno da prática de plantio nessa área, conforme relata $\mathrm{M}$. (trabalhador acampado, 26 anos):

M.: Ano passado, eu plantei ali (aponta para a faixa de terra), ele... plantei uma meia cova de terra, ele achou ruim, o gado pulava, eu botava prá fora, passava a noite correndo atrás do gado aí prá... tangendo aí prá fora do meu feijão, aí ele... ele via isso, uma vez ele viu mesmo... uma vez ele veio olhar lá o meu (trecho incompreensivel) serviço ali, e viu... viu uma rês dentro do meu feijão, comendo meu feijão lá e ele mesmo botou prá fora e de tarde veio... veio me provocar aqui porque eu tinha plantado ali, ali. Ele não queria que ninguém plantasse e... é, é isso, que ele f... queria me dar uma cadeia, que ele ia dar parte da polícia, esse negócio prá fazer pressão, esses negócio assim, mais pressão. Que polícia não ia me prender porque eu tava, porque eu tinha plantado ali meia cova de feijão ali. Foi isso.

Foi comum, durante o período das observações de campo, constatar trabalhadores realizando atividades agrícolas nessa faixa de terra. No entanto, os pontos de tensão se intensificam quando tais práticas de "tentativa de incorporação do território" se dão para além dessa faixa.

Muitas das ações de caça, pesca, coleta de frutos, de madeira e de palha para reforma e confecção de barracas têm sido alvo de contestação tanto por parte da militância do MST quanto do gerente da fazenda e até mesmo, de alguns acampados. A despeito de ser um preceito não entrar na terra, pudemos registrar trabalhadores ultrapassarem a faixa de terra para realizar alguma das atividades acima descritas. A fala de A. (trabalhadora acampada, 23 anos) complementa nossas observações:

A.: (...) Porque aqui a gente não pode mexer em palha, n/é? A gente não pode entrar, dessa cerca pra lá a gente não pode entrar. Tem uma cerca aí que a gente só pode entrar dela pra cá. Quando a gente vai pegar um... até lenha pra gente cozinhar, n/é? É uma dificuldade também, uma prioridade que a gente temos aqui porque nem entrar dentro da fazenda pra pegar lenha a gente não pode, n/é? E na hora que a gente vai pegar um pau de lenha pra gente cozinhar, que a gente é... é descoberto, que o gerente pega a gente, quando a gente pensa que não, o camburão já tá aqui, n/é?

A.: (...) Que agora tá chegando pessoa pra fazer barraca, tem de tirar palha, a gente não pode tirar pra que eles vejam, n/é? Mas, às vez, quando passa e que vê as palha nova, ele sabe que foi daí. Aí, já que não, o camburão chega aqui, n/é? pra gente.

J.: Mas aí, leva alguém assim quando vem o camburão?

A.: Não. Porque a gente conversa, n/é? A gente diz que a gente não vai mais fazer aquilo. Eles dão conselho, n/é? Porque eles também até entende o sofrimento da gente, n/é? Também. Aconselham que a gente não faça mais, se fez, mas não faça mais se não prejudica a gente, quanto mais a gente fizer coisas assim, vai demorar mais pra gente, n/é? E até, graças a Deus, até aqui ainda não foi assim, sobre essas coisa ainda não foi preso, n/é? Nenhum companheiro.

J.: Então, assim, quando alguém entra é escondido?

A.: É, quando a gente entra é escondido. É. Nem pra tirar lenha a gente não pode entrar pra tirar, se entra tem de ser escondido, porque se eles virem dá problema pra nós, enfrentamos outro problema.

Alguns dessas práticas são criadas em meio às necessidades específicas dos trabalhadores, como: o ato de cozinhar e, para tanto, precisar de lenha; alimentar-se com os frutos e peixes da propriedade quando não dispõem de alimentos no acampamento; construção e reforma das barracas através da madeira e palha.

Por se tratarem de questões emergenciais para os acampados, certamente que buscarão formas de driblar tanto a posição da militância quanto do gerente da fazenda e o fazem por meio de artifícios múltiplos, diversos que tanto desagradam o movimento quanto o gerente:

DIÁLOGO 01 (I., trabalhador acampado, 34 anos)

J.: O que você acha, assim, das pessoas que entram aí, pra tirar lenha?

I.: É... eu acho que isso é certo e é comum, n/é? Que nós precisa, nós não tem um fogão à gás, e mesmo que tivesse o dinheiro não tinha, n/é? as condições de coisar. Eu acho que a lenha, uma palha de coco, uma vara, uma forquilha, isso é normal. Agora, que eles não querem, mas nós tira assim mesmo. O que queria ou que não queria, nós vai por ali, na boca da noite (grifo nosso), tira e vai se embora.

Desse modo, pudemos constatar que a tentativa de produção de um modelo subjetivo para o conjunto do acampamento encontra focos de resistência, especialmente quando esse modelo não inclui as especificidades do grupo acampado. Modos singulares de resposta são produzidos por meio de práticas cotidianas que não se subjugam.

Por esse aspecto, os trabalhadores acampados terão suas subjetividades confrontadas com elementos de diferentes ordens que entram em conexão na vivência do acampamento, a exemplo da participação das mulheres na luta, para as quais a conquista da terra diz respeito a uma alternativa de redimensionamento do modelo de relação com 
seus antigos companheiros, marcada, como destacam seus depoimentos, por uma forte dependência e assujeitamento. Por outro lado, encontramos alguns homens realizando atividades comumente tidas como femininas por seu universo cultural, como cozinhar, arrumar a barraca, lavar roupas e cuidar de crianças, sendo a execução de tais atividades vista com algum estranhamento, pois insere o homem num campo de experimentações até então não vivido, conforme relata o $\mathrm{Sr}$. A. (trabalhador acampado, 54 anos):

J.: O que foi que mudou na vida do senhor, o que ficou diferente depois que veio pro acampamento?

A.: É, o que ficou diferente você sabe, é... o, é... que ficou diferente pra mim, sabe, que quando eu vivia em casa, na minha casa mesmo, n/é? era muito... pra mim era muito feliz. Aí, depois que eu vim pra aqui a dificuldade é maior, n/é? A diferença é essa, a dificuldade é maior. Eu vou trabalhar, quando eu chego em casa vou cuidar da minha bóia, n/é? Sozinho vou cuidar da minha bóia.

O acampamento, nesses termos, passa a provocar seus habitantes pelas inúmeras questões que vão surgindo na sua vivência diária, ligadas ou não às proposições dos dirigentes do MST. São situações concretas que vão demandando dos acampados resolutividade e convocam suas subjetividades a contornos outros que sustentem a experiência do acampamento. É, portanto, nesse espaço, em meio a precariedades e desafios constantes, que os trabalhadores desenvolvem formas de resistir na área ocupada, orientadas ou não pelo MST.

Nesse processo de produção da resistência, dois elementos se destacaram em nossas observações no sentido de pôr as subjetividades dos trabalhadores em movimento: a apropriação espacial do acampamento e o modo de participação do corpo dos trabalhadores nessa apropriação. Por se instalar numa margem de rodovia, o acampamento acaba por desconstruir uma racionalidade típica de um espaço de fluxo e trânsito, e não de parada para abrigar vidas humanas. Racionalidade que impõe modos de apropriação do espaço. Na margem da rodovia, uma outra racionalidade emerge: a produção de um lugar no espaço de poder (Carlos, 1996).

Um lugar que se vai marcando pela construção de um campo referencial em termos de nele cultivar um acolhimento a despeito de toda sua precariedade. Lançados à margem (literalmente) ou à vivência de uma subjetividadelixo (Rolnik, 2003), os mesmos acampados experimentam fazer da vida à margem um ensaio de desfiliação a tal subjetividade, ou para dizer com Pelbart (2003, p.32), "quando o poder toma de assalto a vida, a resistência invoca o poder da vida e de suas múltiplas forças".

Isso está especialmente colocado pela maneira de como os trabalhadores dimensionam a disposição espacial das barracas (parentes e familiares próximos), algumas confec- cionadas e arrumadas de modo a lembrar uma casa com seus compartimentos, a realização de plantio na margem da rodovia e em uma pequena faixa de terra da propriedade reivindicada e a criação de pequenos animais. $\mathrm{Ou}$ seja, a recomposição de um modo de vida orientado por uma subjetivação camponesa, suprimida e precarizada pelo capital.

Nessa apropriação, o corpo é atravessado pelas intensidades que um outro uso e duração de uso da rodovia implicam, pois é ele que vivencia a "loucura" (termo usado por um trabalhador acampado) de habitar um acampamento e se oferecer aos limites de suas adversidades (alterações climáticas, fome, moradias em barracas precárias, riscos de atropelamento, despejos judiciais). Mesmo que a barraca possa promover uma proteção ao acampado, especialmente à noite, o momento mesmo de repouso do corpo é destacado por alguns trabalhadores como causador de insegurança, uma vez que ficam à mercê da fragilidade que o acampamento aponta: receio de que transeuntes possam atear fogo nas barracas ou de que algum carro venha com alguma delas se chocar. ${ }^{5}$ Outras experimentações subjetivas emergem com a alteração de alguns códigos culturais comumente vivenciados (Miele \& Guimarães, 1998), a exemplo da indistinção, em alguns momentos, das esferas público-privado, expressa na realização coletiva de tarefas entre homens e mulheres, convivência com outras famílias na mesma barraca, compartilhamento de experiências íntimas que toma foro público dado pela proximidade das barracas e o convívio em vizinhança. Um território que ressalta, portanto, aproximações físicas entre as pessoas que retomam suas inter-relações, criando e desfazendo laços de solidariedade, seja pelo estranhamento da experimentação, seja pelo surgimento de novas subjetividades e de suas sucessivas dobras (Deleuze, 1986).

\section{Considerações Finais}

É importante ressaltar que, para uma discussão acerca do tema da subjetividade na perspectiva pela qual elegemos, o MST torna-se um fenômeno importante, já que se pondo como uma instância de subjetivação torna-se possível construirmos uma cartografia do modo como sua práxis coletiva reverbera nas subjetividades dos trabalhadores da base social do movimento.

Nesse sentido, como mostrado ao longo do texto, dois elementos ganharam destaque em nossa investigação: a tentativa de subjetivação via o modelo do Sem Terra e como os trabalhadores acampados são afetados tanto por esse modelo quanto pela vivência do acampamento em sua realidade sensível no âmbito da apropriação desse espaço e do uso do corpo nessa apropriação.

Esses dois elementos apontam uma discussão que, a nosso ver, torna-se imprescindível para pensarmos o MST enquanto um movimento social inspirado no plano da ma- 
cropolítica. Isso se reflete em suas categorias de análise baseadas em "condicionantes (ou determinações) econômico-estruturais" (Scherer-Warren, 1998, p.223), ou como um resultado das contradições entre o sistema político e econômico do capitalismo (Silva, 2000).

Baseados em Scherer-Warren (1998), podemos resumir que esse enfoque aborda um sujeito de ordem coletiva e generalizado (camponeses, proletariados), ou seja, em termos de pertencimento a uma classe social, que os processos sociais se dão numa curva longa de espaço/tempo e que a "utopia emancipatória" (p.224) pretende uma transformação social de caráter revolucionário e de efeito prolongado. No entanto, como assinala Silva (2000), ao destacar essa perspectiva estrutural, há uma perda significativa dos aspectos político-subjetivos que informam o caráter de representatividade dos movimentos sociais. Ademais, desconsidera-se que essas lutas sociais são permeadas por experiências do cotidiano, por "concepções, percepções e ações dos agentes" (p.156).

Ao tomarmos as considerações de Guattari (Guattari \& Rolnik, 1986) sobre os novos movimentos sociais, o autor reconhece que há neles uma tentativa de produção de modos de subjetividade "originais e singulares" ou "processos de singularização subjetiva" (p.45). Isso quer dizer que esses grupos estão na posição de redimensionar as relações de força social, no sentido de promover novos arranjos e novas formas de existir que escapem a modelizações provenientes da máquina capitalista. $\mathrm{O}$ autor destaca que as demandas dos movimentos sociais não podem se resumir, unicamente, à busca de uma referência identitária, mas de algo que envolve toda uma engrenagem de funcionamento da sociedade. Faz uso da idéia de "devir", justamente como a possibilidade que esses processos têm de manterem-se singulares ou não. Assim, fala de um devir mulher, devir negro, devir homossexual (poderíamos pensar num devir sem-terra?) e levanta a hipótese de que há entre esses devires "vias de passagem, vias de comunicação inconsciente" (Guattari \& Rolnik, 1986, p.74), para além de uma justificativa cultural, racial, religiosa que explicasse a existência de tais "minorias". São essas vias de passagens entre os devires que permitem uma ação dessas "minorias" para além de uma "identidade de classe" (poderíamos, novamente, pensar numa via de passagem entre um devir-mulher e um devir sem-terra?).

Estamos, desse modo, no campo do que nomeia de micropolítica, que visa o agenciamento desses devires, busca promover sua conexão, um apoio mútuo entre tais devires que estariam em condições de promover mutações das subjetividades para além das segregações identitárias, que se encontram legitimadas pelo modelo de funcionamento das sociedades capitalistas. A micropolítica atua, conforme Deleuze e Guattari (1996), numa escala molecular, em que se busca destacar as minúcias, os processos singulares, as linhas de fuga, localizados nos pequenos grupos sem, con- tudo, perder de vista sua co-extensividade ao campo social maior.

Nesse caso, resta-nos indagar qual a posição do MST a respeito dos desdobramentos de suas ações junto à base social do movimento. Desdobramentos esses que, como apontamos, configuram o campo da micropolítica, em que as multiplicidades, os devires e as intensidades são elementos presentes e compõem um movimento de resistência no processo de luta pela terra.

Isso nos possibilita uma compreensão de que as práticas cotidianas dos trabalhadores acampados revelam focos de tensão em relação aos princípios organizativos do movimento, em virtude de sua perspectiva macropolítica. Esta, por sua vez, ao tomar os Sem Terra como uma categoria social homogênea, que precisa avançar para um modelo coletivista de sociedade, acaba por não privilegiar as diversidades culturais, as singularidades ou os novos arranjos subjetivos que emergem como efeito de sua atuação que, do nosso ponto de vista, configuram-se como elementos imprescindíveis de sustentação do movimento enquanto uma experiência de resistência no seio mesmo do capital.

Entretanto, para além do potencial assegurador das forças de resistência e transformação do MST, é preciso reconhecer, principalmente, que a produção incessante de novos territórios existenciais na vivência do acampamento revela uma certa capacidade de "viver para o ensaio" (Pelbart, 2000, p.20), revela formas de vida emergentes que a despeito de todas as adversidades e imprevisibilidades, suportam ser afetadas, desassossegadas, enfrentam o intolerável, aquilo que uma "gorda saúde" (Deleuze, 1997) não possibilitaria, pois incapaz de ser atravessada pelos excessos. Nesse sentido, Pelbart (1989) nos aponta que

A saúde não é só a capacidade de evitar catástrofes, mas também a de criar novas normas arriscando a própria vida. Há aí a exuberância, criatividade e generosidade vitais que nos distanciam irremediavelmente da noção de saúde como estabilidade. O normal é aquele que sente que é mais do que normal, que pode arriscar porque tem a plasticidade necessária para fazê-lo. Faz parte da saúde, diz Canguilhem, poder abusar da saúde. É o doente, e não o são, que economiza, pois tende a reduzir suas normas e estabilizar suas condições de vida (p.213)

Assim, consideramos que a experiência vivida no acampamento produz linhas de fugas, subjetividades em movimento, invenções cotidianas que refletem uma "saúde", muitas vezes imperceptível, invisível, porque intensiva, aos sentidos daqueles cuja vida encontra-se aprisionada por si próprios.

\section{Notas}

1. Linhares e Silva (1999) destacam o crescimento populacional de grandes cidades brasileiras, atribuindo tal fenômeno aos pro- 
blemas oriundos da concentração de terra, condições de vida no campo e falta de trabalho no setor agrícola. Se na década de 1940, a população urbana era de $31,2 \%$, em 1990, registrou $75,4 \%$.

2. Há uma distinção ortográfica e conceitual entre o termo sem-terra (com hífen) e Sem Terra (sem hífen, maiúsculo). Enquanto o primeiro alude à categoria social de trabalhador rural não-proprietário de uma unidade de produção ou o é em condições precárias, o segundo faz alusão a uma referência identitária do trabalhador ou trabalhadora que incorpora os princípios do MST. Essa distinção será adotada neste trabalho.

3. Os princípios organizativos do MST referem-se às posições políticas e ideológicas (Stédile \& Fernandes, 1999) que orientam sua atuação e funcionamento interno. São eles: Direção Coletiva, Divisão de Tarefas, Disciplina, Realização de Estudos, Luta de Massas e Vinculação com a Base Social do Movimento.

4. A ocupação inicial deu-se no interior da propriedade em que ocorreram dois despejos dos trabalhadores. Nessa época, foi editada uma medida provisória do governo federal em que as terras "invadidas" teriam o prazo de vistoria para possível desapropriação adiado em dois anos. Desse modo, os trabalhadores e os militantes do MST optaram por permanecer acampados na faixa de terra entre a propriedade reivindicada e a rodovia.

\section{Referências}

Bogo, A. (2001). O MST e a Cultura. In: Bogo, A. (Ed.). Caderno de Formação $n^{\circ} 34$. Veranópolis, RS.

Bonavigo, E.A. (1998). Produção sócio-histórica da "Cooperação agrícola" no Acampamento Annoni e no Assentamento 16 de Março: Práticas Cotidianas e Produção de Subjetividades. Dissertação de Mestrado não-publicada, Universidade Estadual do Rio de Janeiro. Rio de Janeiro, RJ.

Caldart, R.R. (2000). Pedagogia do Movimento Sem Terra. Petrópolis: Vozes.

Carlos, A.F.A. (1996). O lugar no / do mundo. São Paulo: Hucitec.

Certeau, M. (1996). A invenção do cotidiano: artes de fazer. Petrópolis: Vozes.

Deleuze, G. (1986). As dobras ou o lado de dentro do pensamento (subjetivação). In: Deleuze, G. (Ed.), Foucault (pp.101-130). São Paulo: Brasiliense.

Deleuze, G. (1997). Crítica e Clínica. São Paulo: Ed.34.

Deleuze, G. \& Guattari, F. (1996). Micropolítica e segmentaridade. In: Deleuze, G. \& Guattari, F. (Eds.), Mil Platôs: capitalismo e esquizofrenia (pp.83-115). São Paulo: Ed34.

Fernandes, B. (2000). A Formação do MST no Brasil. Petrópolis, RJ: Vozes.

Fernandes, B.M. \& Stédile, J.P. (1999). Brava Gente: a trajetória do MST e a luta pela terra no Brasil. São Paulo: Fundação Perseu Abramo.

Foucault, M. (1984). Vigiar e Punir: História das violências nas prisões. Petrópolis: Vozes.

Gaiger, L. (1994). I. A Práxis coletiva dos Sem-Terra: rumo à unidade ou à heterogeneidade cultural? Cadernos de Sociologia, 6., 111-203.

Graziano da Silva, F. (1981). A Modernização dolorosa: estrutura agrária e fronteira agrícola e trabalhadores rurais no Brasil. Rio de Janeiro: Jorge Zahar.

Guattari, F. (2000). Heterogênese. In: Guattari, F. (Ed.), Caosmose: um novo paradigma estético (pp.11-95). São Paulo: Ed. 34.

Guattari, F. (1997). As Três Ecologias. São Paulo: Papirus.
Guattari, F. \& Rolnik, S. (1986). Micropolítica: Cartografias do desejo. Petrópolis: Vozes.

Haesbaert, R. (2004). Território e desterritorialização em Deleuze e Guattari. In: Haesbaert, R. (Ed.), O Mito da desterritorialização: do "Fim dos Territórios à Multiterritorialidade (pp.99-141). São Paulo: Bertrand Brasil.

Leite, J. (2003). Produção de subjetividade em trabalhadores rurais na condição de luta pela terra. Dissertação de mestrado não-publicada, Universidade Federal do Rio Grande do Norte. Natal, RN.

Leite, J.F. \& Dimenstein, M.(2003). Procesos de subjetivación en la lutcha por la Tierra en Brasil. Subjetividad y Cultura, 20, 32-43.

Linhares, M.Y. \& Silva, F. C.T. (1999). Terra Prometida: uma história da questão agrária no Brasil. Rio de Janeiro: Campus.

Miele, N. \& Guimarães, F.M. (1998). As Mulheres nos Assentamentos Rurais: o antes e o depois. In: Ieno, G. \& Bamat, T. (Eds.), Qualidade de Vida e Reforma Agrária na Paraíba (pp.205-243). João Pessoa: UNITRABALHO.

Nardi, H.C. (2002). Trabalho e Ética: Os processos de Subjetivação de duas gerações de Trabalhadores metalúrgicos e do Setor informal (1970-1999). Tese de Doutorado não-publicada, Universidade Federal do Rio Grande do Sul. Porto Alegre, RS.

Navarro, Z. (1998). Dilemas de um protagonista da luta pela terra. In: Costa, L.F.C. \& Santos, R. (Eds.), Política e reforma agrária (pp.181-184). Rio de Janeiro: Mauad.

Pelbart, P.P. (1989). Da clausura do fora ao fora da clausura: loucura e desrazão. São Paulo: Brasiliense.

Pelbart, P.P. (2000). A vertigem por um fio. Políticas da subjetividade contemporânea. São Paulo: Iluminuras.

Pelbart, P.P. (2003). Subjetividade e Pós-modernismo. In: Arán, M. (Ed.), Soberanias (pp.31-39). Rio de Janeiro: Contra Capa.

Rolnik, S. (2003). A vida na berlinda. In Arán, M. (Ed.), Soberanias (pp.259-267). Rio de Janeiro: Contra Capa.

Rolnik, S. (2000). Novas figuras do caos - mutações da subjetividade contemporânea. In: Fonseca, T.M.G., Kirst, P.G. (Eds.), Formas de ser e habitar a contemporaneidade (pp.63-70). Porto Alegre: Ed. Universidade/UFRGS.

Scherer-Warren, I. (1998). Novos rumos da pesquisa sobre ações coletivas rurais. In: Costa, L.F.C. Santos, R. (Eds.), Política e reforma agrária (pp.221-240). Rio de Janeiro: Mauad.

Silva, J.M. (2003). Cultura e territorialidades urbanas: uma abordagem da pequena cidade. Revista de História Regional, 5. Disponível em: http://www.rhr.uepg.br/v5n2/joseli.htm, 04/06/2003.

Silva, P.R.P. (1997). Luta pela Terra: a busca da cidadania. Os conflitos de terra - 1960 a 1990. Vivência, 11, 59-74.

Silva, S. (2000). A Política e os Movimentos Sociais: o contexto dos discursos, da representação social e do conflito. Cadernos de Estudos Sociais Recife, 16, 147-172.

Jáder Ferreira Leite é Doutorando em Psicologia Social/UFRN, Professor de Psicologia na Universidade Potiguar e Faculdade Câmara Cascudo. jaderfleite@hotmail.com

Magda Dimenstein é Doutora em Saúde Mental pelo IPUB/UFRJ. Professora e Coordenadora do Programa de Pós-Graduação em Psicologia/UFRN. Endereço para correspondência: Departamento de Psicologia, campus universitário, Lagoa Nova, Natal, RN, 59078970. magdad@uol.com.br 
Leite, J.F.; Dimenstein, M. "Subjetividade em Movimento: o MST no Rio Grande do Norte"

Subjetividade em movimento: o MST no Rio Grande do Norte

Jáder Ferreira Leite e Magda Dimenstein

Recebido: 26/04/2005

$1^{\mathrm{a}}$ revisão: 10/08/2005

Aceite final: 13/01/2006 